\title{
Long-term Outcomes and Factors Affecting the Survival of Patients with Mucosal Esophageal Squamous Cell Carcinoma
}

\author{
Ga Hee Kim¹, Hee Kyong Na¹, Ji Yong Ahn¹, Jeong Hoon Lee ${ }^{1}$, Kee Wook Jung' ${ }^{1}$, Do Hoon Kim¹, Hyeong Ryul \\ $\mathrm{Kim}^{2}$, Kee Don Choi', Ho June Song' ${ }^{1}$, Yong-Hee Kim², Gin Hyug Lee ${ }^{1}$, Hwoon-Yong Jung ${ }^{1}$, and Seung-II Park ${ }^{2}$ \\ Departments of ${ }^{1}$ Gastroenterology and ${ }^{2}$ Thoracic and Cardiovascular Surgery, Asan Medical Center, University of Ulsan College of \\ Medicine, Seoul, Korea
}

\section{Article Info}

Received August 6, 2020

Revised October 6, 2020

Accepted October 7, 2020

Published online January 22, 2021

\section{Corresponding Author}

Ho June Song

ORCID https://orcid.org/0000-0002-3195-8794

E-mail hjsong@amc.seoul.kr

Yong-Hee Kim

ORCID https://orcid.org/0000-0003-2177-4876

E-mail kimyh67md@hotmail.com
Background/Aims: Data regarding the prognosis of early esophageal cancer are lacking. This study investigated the long-term outcomes and factors affecting the survival of patients with mucosal esophageal squamous cell carcinoma (T1aESCC).

Methods: We analyzed the clinical and tumor-specific parameters of 263 patients who received surgical resection (SR; $n=63$ ) or endoscopic resection (ER; $n=200)$ for T1aESCC. Underlying comorbidities were scored using the Charlson comorbidity index $(\mathrm{CCl})$. Overall survival $(\mathrm{OS})$ was the primary outcome, and multivariate regression analysis was performed to predict factors for OS.

Results: Of the study patients (age, $64.5 \pm 8.0$ years), the CCI was $1.0 \pm 1.4$ in the ER group and $0.6 \pm 0.9$ in the SR group ( $p=0.107)$. The 5 -year OS rate during follow-up ( $54.4 \pm 20.4$ months) was $85.7 \%$ (ER group, $86.8 \%$; SR group, $82.4 \%$; $p=0.631$ ). The cumulative 5 -year incidence of esophageal cancer recurrence was $10.5 \%$ in the ER group (vs $0 \%$ in the SR group). The overall mortality rate was $12.9 \%$ (ER group, $12.0 \%$; SR group, $15.9 \% ; p=0.399$ ). The most common cause of mortality was second primary cancers in the ER group (75\%) and organ dysfunction or postoperative complications in the SR group (70\%). According to multivariate analysis, only $\mathrm{CCl}$ was significantly associated with OS $(p<0.001)$. The 5 -year OS rate in patients with a $\mathrm{CCI}>2$ and in those with a $\mathrm{CCl} \leq 2$ was $60.2 \%$ and $88.2 \%$, respectively $(p<0.001)$. The treatment method (ER vs $\mathrm{SR}$ ) was not a significant affecting factor ( $p=0.238)$.

Conclusions: The long-term prognosis of patients with T1aESCC was significantly associated with underlying comorbidities. (Gut Liver 2021;15:705-712)

Key Words: Esophagus; Squamous cell carcinoma; Endoscopic mucosal resection; Esophagectomy; Prognosis

\section{INTRODUCTION}

Recently, the diagnosis of early-stage esophageal cancer is increasing due to screening endoscopy in Korea and Japan. ${ }^{1-3}$ Resection of mucosal esophageal squamous cell carcinoma (T1aESCC) can be performed, either by surgical or endoscopic method. ${ }^{4,5}$ Esophagectomy with locoregional lymph node dissection is the standard treatment of T1aESCC. ${ }^{6}$ In previous studies, patients with ESCC with mucosal invasion showed favorable prognosis and high 5 -year survival rates of up to $85 \%{ }^{7,8}$ As a result of high morbidity and mortality rates with esophagectomy, endoscopic resection (ER) has recently become an alternative to surgical resection (SR) and offers superior safety and acceptable oncologic outcomes, especially confining the tumor depth to mucosa. ${ }^{9}$ However, there has been no data suggesting factors affecting the long-term prognosis of T1aESCC. Additionally, only some several retrospective studies have compared ER to SR in treating T1aESCC. ${ }^{10,11}$

In the present study, we investigated the long-term outcomes and factors affecting survival in patients with TlaESCC who were treated with ER versus those treated with SR. 


\section{MATERIALS AND METHODS}

\section{Study design and population}

Using a prospectively collected esophageal cancer database between January 2012 and December 2016, patients who underwent ER or up-front esophagectomy for the treatment of esophageal cancer at Asan Medical Center were reviewed. During the study period, 254 patients underwent ER and 417 underwent up-front esophagectomy. ER was indicated when superficial ESCC was less than 3 $\mathrm{cm}$ in size without obvious evidence of submucosal invasion on endoscopic ultrasound. The presence of regional or distant lymph node metastasis was detected using chestabdomen computed tomography (CT) and positron emission tomography-CT scans. For equivocal cases of lymph node metastasis, an endoscopic ultrasound-guided fine needle aspiration/biopsy was performed. Up-front surgery was provided for the cT1-2N0M0 stage. Of 254 patients in the ER group, 54 were excluded due to submucosal and/ or lymphovascular tumor invasion $(\mathrm{n}=28)$, low-grade dysplasia $(n=16)$, adenocarcinoma $(n=4)$, no residual tumors $(\mathrm{n}=5)$, and preoperative chemo-radiotherapy $(\mathrm{n}=1)$. In the SR group, 354 patients were excluded due to a deeper invasion depth than the submucosa $(n=324)$, adenocarcinoma $(n=21)$, and additional surgery for non-curative ER $(n=9)$. Finally, a total of 263 T1aESCC cases (200 ER and 63 SR) were included. A flowchart of patient enrollment is shown in Fig. 1. The Institutional Review Board of Asan Medical Center approved the protocols of this (IRB number: 20190356). The informed consent was waived because of the retrospective design.

\section{Procedures of endoscopic and surgical resections}

All tumors were evaluated by chromoendoscopy using Lugol solution and/or narrow-band imaging before ER to determine the exact tumor margin. For ER, a single-channel endoscope (GIF-H260 or GIF-HQ290; Olympus, Tokyo, Japan) was used. Briefly, circumferential marking of the lesion was performed; then, normal saline containing a mixture of indigo carmine and epinephrine $(0.01 \mathrm{mg} / \mathrm{mL})$ was injected into the submucosal layer, followed by circumferential incision of the lifted mucosa with a hook knife (Olympus) or insulation-tipped knife (Olympus). Then, submucosal dissection was conducted using an insulation-tipped knife (Olympus). The VIO 300D (Erbe Elektromedizin GmbH, Tübingen, Germany) system or the A UES-30system (Olympus) was used as the electrosurgical unit. Hemostatic forceps (FD-410LR; Olympus) were used to coagulate the visible or bleeding vessels on the artificial ulcers.

The surgical method was based on the transthoracic approach (Ivor Lewis operation or McKeown operation), and the transhiatal approach was used for patients in whom the transthoracic approach was difficult. Minimally invasive robot-assisted esophagectomy was considered when the patients and their families agreed to the procedure and the tumor characteristic was indicated for a minimally invasive approach. After resection of esophageal cancer, all patients underwent follow-up endoscopy and chest-abdomen CT to evaluate tumor recurrence every 6 months for the first 2 years and annually thereafter until 5 years.

\section{Pathological evaluation and definition}

Tumor size, presence of lymphovascular invasion, depth of invasion, and histologic differentiation were evaluated on the resected specimens. The depth of tumor invasion was classified as intraepithelial (m1), invading the lamina propria (m2), muscularis mucosae (m3), or submucosa. Lymphovascular invasion was indicated by the presence of tumor cells within the lymphovascular structures. The degree of differentiation was determined using the World Health Organization classification. ${ }^{12}$

Metachronous recurrence was defined as esophageal cancers that developed 1-year post-resection at a location different from the primary resection site. Locoregional recurrence was defined as recurrence of the primary tumor or metastasis to regional lymph nodes, as observed on

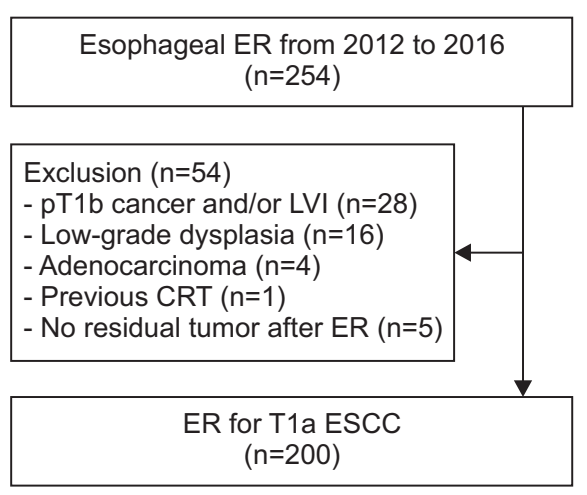

Fig. 1. Flowchart of the study groups. $E R$, endoscopic resection; SR, surgical resection; LVI, lymphovascular invasion; CRT, concurrent chemoradiation therapy; ESCC, esophageal squamous cell carcinoma. 
endoscopy, chest-abdomen CT, or positron emission tomography-CT. Second primary cancer (SPC) was defined as tumors clearly designated as malignant on histologic examination and exclude the possibility of esophageal cancer metastasis.

\section{Statistical analysis}

Overall survival (OS) was the primary outcome and the recurrence-free survival was the secondary outcome. The outcomes were calculated from the first day of procedure until the date of events or the most recent documented follow-up.

Baseline variables are presented as mean \pm standard deviation or number (\%). To compare variables between the study groups, the analysis of variance or the Student t-test was used for continuous variables and the Fisher exact test or the chi-square test was used for categorical variables. The Kaplan-Meier method was used to calculate the OS, which was compared using the log-rank test. In order to identify factors significantly associated with OS, univariate and multivariate analyses with backward elimination using logistic regression analysis were performed. Cox regression analysis was performed to determine the significant factors affecting survival. The results were expressed by estimating the hazard ratios and 95\% confidence intervals. All p-values were two-sided and those less than 0.05 were considered significant. IBM SPSS Statistics for Windows, version 21.0 (IBM Corp., Armonk, NY, USA) was used for all statistical analyses.

\section{RESULTS}

\section{Patient characteristics}

Table 1 lists baseline characteristics of the 263 patients, whose mean age was $64.5 \pm 8.0$ years and $93.5 \%$ of whom were male. Tumor size was $2.1 \pm 1.4 \mathrm{~cm}$ in the ER group and $3.0 \pm 1.5 \mathrm{~cm}$ in the SR group ( $\mathrm{p}<0.001)$. Endoscopic flat-type lesions (88.0\% vs $34.9 \%)$ and differentiated tumors $(99.5 \%$ vs $93.6 \%$ ) were more common in the ER group than in the SR group. Tumors were confined in m1-2 mucosal layers for $85.0 \%$ in the ER group and $72.3 \%$ in the SR group $(p<0.001)$. We found no significant differences in terms of age, sex, smoking status, alcohol consumption, Charlson comorbidity index (CCI), multiplicity of lesions, and presence of lymphovascular invasion between the groups.

\section{Comparison of immediate therapeutic outcomes}

In patients undergoing $\mathrm{ER}$, the procedure time was $38.3 \pm 24.2$ minutes (vs $311.8 \pm 45.7$ minutes in SR) and the postprocedural hospital stay was $4.0 \pm 2.3$ days (vs $16.9 \pm$ 9.9 days in SR). The rate of $\mathrm{R} 0$ resection was $91 \%$ in the

Table 1. Baseline Clinicopathologic Characteristics of the Study Patients

\begin{tabular}{|c|c|c|c|}
\hline Characteristics & Endoscopic resection ( $n=200)$ & Surgical resection $(n=63)$ & $\mathrm{p}$-value \\
\hline Age, yr & $64.9 \pm 8.3$ & $63.2 \pm 7.1$ & 0.194 \\
\hline Male sex & 185 (92.5) & 61 (96.8) & 0.257 \\
\hline Weight, kg & $63.1 \pm 10.0$ & $65.9 \pm 10.4$ & 0.064 \\
\hline $\mathrm{BMI}, \mathrm{kg} / \mathrm{m}^{2}$ & $22.9 \pm 3.1$ & $23.8 \pm 3.1$ & 0.054 \\
\hline Charlson comorbidity index & $1.0 \pm 1.4$ & $0.6 \pm 0.9$ & 0.107 \\
\hline Smoking & 164 (82.0) & 54 (85.7) & 0.569 \\
\hline Alcohol consumption & $173(86.6)$ & 55 (87.3) & 0.536 \\
\hline Tumor location & & & $<0.001$ \\
\hline Upper third & 19 (9.5) & $4(6.3)$ & \\
\hline Middle third & $72(36.0)$ & $36(57.1)$ & \\
\hline Lower third & 109 (54.5) & 23 (36.5) & \\
\hline Tumor size, cm & $2.1 \pm 1.4$ & $3.0 \pm 1.5$ & $<0.001$ \\
\hline Tumor gross type & & & $<0.001$ \\
\hline Flat & $176(88.0)$ & 22 (34.9) & \\
\hline Non-flat & $24(12.0)$ & $41(65.1)$ & \\
\hline Differentiation & & & 0.013 \\
\hline Well to moderately & 199 (99.5) & $59(93.6)$ & \\
\hline Poorly & 1 (0.5) & $4(6.4)$ & \\
\hline Multiplicity of lesion & $10(5.0)$ & $5(7.9)$ & 0.361 \\
\hline Depth of invasion & & & $<0.001$ \\
\hline Intraepithelial (m1) & 85 (42.5) & $4(2.5)$ & \\
\hline Lamina propria (m2) & 85 (42.5) & 44 (69.8) & \\
\hline Muscularis mucosa (m3) & $30(15.0)$ & 15 (23.8) & \\
\hline Lymphovascular invasion & $1(0.5)$ & 2 (3.2) & 0.107 \\
\hline Lymph node metastasis & NA & $4(6.3)$ & NA \\
\hline
\end{tabular}

Data are presented as mean \pm SD or number $(\%)$.

BMI, body mass index; NA, not applicable. 
ER group and $100 \%$ in the SR group (Table 2). Procedurerelated immediate adverse events were noted in $10.0 \%$ of the ER group and $38.1 \%$ of the SR group $(\mathrm{p}<0.001)$. Severe undesirable effects including pulmonary, infectious, and hemorrhagic adverse events were $1.5 \%$ in the ER and $11.1 \%$ in the SR groups $(\mathrm{p}<0.001)$. Esophageal stricture was the most common adverse event in patients receiving ER (7.5\%; vs 3.2\% in SR). Procedure-related immediate mortality was reported at $4.8 \%$ in the SR group ( $0 \%$ in the ER group; $\mathrm{p}=0.013$ ).

\section{Long-term outcomes}

During follow-up $54.4 \pm 20.4$ months, the 5 -year OS rate of the both groups of patients was $85.7 \%$. The 5 -year OS rate was not significantly different between the groups (ER group, 86.8\%; SR group, 82.4\%; $\mathrm{p}=0.631$ ). The 1 - and 3-year survival rates in the ER and SR groups were 98.0\% versus $93.7 \%$ and $92.9 \%$ versus $90.5 \%$, respectively. Excluding three immediate mortality cases, the 5 -year OS was $86.8 \%$ in ER and $86.5 \%$ in SR groups ( $\mathrm{p}=0.662$ ).

The cumulative 5-year incidence of locoregional recurrence of primary esophageal cancer was $1.5 \%$ and metachronous esophageal cancer recurrence was $9.0 \%$ in the ER group ( $0 \%$ in the SR group) (Fig. 2B). The mean followup period for recurrence was $41 \pm 18.6$ months. During the study period, SPC occurred in 18 patients in the ER groups (9\%) and in six in the SR group (9.5\%).

The overall mortality was $12.9 \%$ (ER group, $12.0 \%$; SR group, 15.9\%; $\mathrm{p}=0.399$ ). Esophageal cancer-related death was not reported in either group during the follow-up period. The most common cause of mortality was SPC in the ER group (75\%) and organ dysfunction or postoperative

Table 2. Immediate Treatment Outcomes

\begin{tabular}{lccc}
\hline \multicolumn{1}{c}{ Variable } & Endoscopic resection $(n=200)$ & Surgical resection $(n=63)$ & p-value \\
\hline Procedure time, min & $38.3 \pm 24.2$ & $311.8 \pm 45.7$ & $<.9$ \\
Postprocedural hospital days, day & $4.0 \pm 2.3$ & $6.9 \pm 9.9$ & $<0.001$ \\
R0 resection & $182(91.0)$ & $24(38.1)$ & 0.009 \\
Adverse events* & $20(10.0)$ & $3(4.8)$ & $<0.001$ \\
Bleeding & $2(1.0)$ & $4(6.3)$ & $2(3.2)$ \\
Leakage & 0 & 0 & $1(1.6)$ \\
Stricture & $15(7.5)$ & 0 & $3(4.8)$ \\
Micro-perforation & $1(0.5)$ & $2(3.2)$ \\
Fistula & 0 & $6(9.5)$ \\
Subcutaneous emphysema & $1(0.5)$ & $6(9.5)$ \\
Pulmonary events & $1(0.5)$ & $1(1.6)$ \\
Wound problem & 0 & $3(4.8)$ \\
Hoarseness & 0 & 0 & 0.013 \\
Chylothorax & 0 & 0 & \\
Severe infection & 0 &
\end{tabular}

Data are presented as mean \pm SD or number $(\%)$.

*Adverse events occurred within 60 days of treatment.
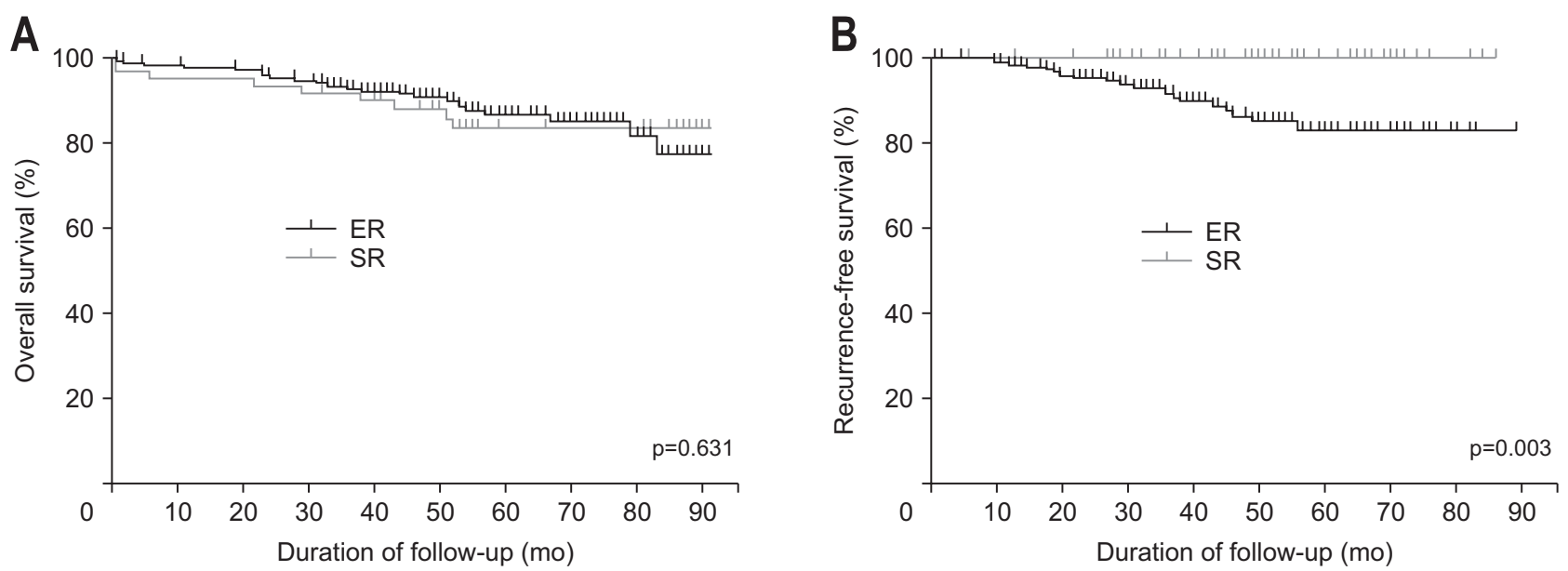

Fig. 2. Kaplan-Meier curves comparing overall survival (A) and recurrence-free survival (B) between the endoscopic resection (ER) and surgical resection (SR) groups. 
complications in the SR group (70\%). The long-term outcomes of the study patients are shown in Table 3 and Fig. 2. The three cases of locoregional recurrence after ER was detailed in the Supplementary Table 1.

\section{Significant factors affecting overall survival}

We calculated multivariate Cox proportional hazard models to identify the factors significantly associated with OS in the overall patients with T1aESCC (Table 4). The following factors were investigated: age, sex, smoking, alcohol consumption, CCI score, tumor size, tumor location, invasion depth, gross shape, differentiation, multiplicity of lesions, lymphovascular invasion, and treatment methods.

CCI was identified as the only significant factor for OS (hazard ratio, 1.61; 95\% confidence interval, 1.30 to 2.01; $\mathrm{p}<0.001$ ) (Fig. 3). The 1-, 3-, and 5-year survival rates in patients with CCI $>2$ and those with CCI $\leq 2$ were $88 \%$ versus $97.9 \%, 80 \%$ versus $93.6 \%$, and $60.2 \%$ versus $88.2 \%$, respectively. The method of treatment (ER vs SR) was not a significant factor for OS $(\mathrm{p}=0.238)$.

\section{DISCUSSION}

In the present study, the 5-year OS rate of patients with T1aESCC was $85.7 \%$ and CCI was the only significant factor affecting survival. There was no difference in the OS between the ER and SR groups.

Esophagectomy is considered the gold standard in the treatment of localized esophageal cancer, particularly superficial tumors. ${ }^{13}$ However, esophagectomy results in mortality and severe morbidity rates of $2 \%$ to $5 \%$ and $30 \%$ to $40 \%$, respectively, which significantly alter patients' quality of life. ${ }^{14-16}$ Compared with SR, ER is a minimally invasive procedure; furthermore, it can perfectly preserve the normal anatomical structures and functions. Patients who underwent ER had shorter postprocedural hospital stays ( $4.0 \pm 2.3$ days), shorter procedure times $(38.3 \pm 24.2$ minutes), and lower immediate adverse event rates (10.0\%). Thus, ER is now considered a first-line treatment modality for technically feasible early-stage of esophageal cancer.

ER is well-suited for superficial cancers confined to the mucosa, as the likelihood of lymph node metastasis is very low. ${ }^{17,18}$ The risk of lymph node invasion is closely associated with the tumor invasion depth, lymphovascular invasion, and histological differentiation. Estimates of lymph node metastasis based on these histopathologic features have been established. In previous studies, lymph node metastasis was noted been found in up to $4 \%$ of cancers in the epithelium (m1) and lamina propria (m2), $0 \%$ to $22 \%$ of cancers invading the muscularis mucosa (m3), and 26\% to $54 \%$ of cancers invading the submucosa. ${ }^{2,19}$ Therefore, $\mathrm{ER}$ is the preferred treatment modality for $\mathrm{m} 1, \mathrm{~m} 2$, and $\mathrm{m} 3$ cancers and relatively indicated for submucosal cancer invasion of up to $200 \mu \mathrm{m} .{ }^{4,5,20,21}$ According to guidelines, esophagectomy and ER are equally recommended for lesions limited to the mucosa for superficial ESCC. ${ }^{20,21}$ In Japan, ER is considered a radical treatment for lesions confined to mucosal epithelium and lamina propria. ${ }^{4}$ Lesions extending up to the muscularis mucosae or lightly infiltrat-

Table 3. Long-term Oncologic Outcomes

\begin{tabular}{|c|c|c|c|}
\hline Variable & Endoscopic resection $(n=200)$ & Surgical resection $(n=63)$ & p-value \\
\hline Follow-up duration, mo & $53.2 \pm 18.9$ & $58.3 \pm 24.4$ & 0.131 \\
\hline Recurrence-free survival, mo & $40.9 \pm 18.7$ & $58.3 \pm 24.4$ & $<0.001$ \\
\hline Cumulative overall survival rate $(\%)$ & & & 0.631 \\
\hline 1 Year & 98.0 & 93.7 & \\
\hline 3 Years & 92.9 & 90.5 & \\
\hline 5 Years & 86.8 & 82.4 & \\
\hline Recurrence of esophageal cancer & $21(10.5)$ & 0 & 0.006 \\
\hline Locoregional & $3(1.5)$ & 0 & \\
\hline Metachronous & $18(9.0)$ & 0 & \\
\hline Cumulative recurrence free survival rate $(\%)$ & & & 0.003 \\
\hline 1 Year & 98.5 & 100 & \\
\hline 3 Years & 91.8 & 100 & \\
\hline 5 Years & 83.2 & 100 & \\
\hline Death & 24 (12.0) & 10 (15.9) & 0.399 \\
\hline Disease-specific death & 0 & 0 & 1.000 \\
\hline \multicolumn{4}{|l|}{ Cause of death } \\
\hline Second primary cancers & 18 (75.0) & $2(20.0)$ & \\
\hline Organ dysfunction & 2 (8.3) & $4(40.0)$ & \\
\hline Postoperative complications & 0 & $3(30.0)$ & \\
\hline Other causes & $4(16.7)$ & $1(10.0)$ & \\
\hline
\end{tabular}

Data are presented as mean \pm SD or number (\%). 
Table 4. Significant Factors of Survival in the Univariate and Multivariate Analyses

\begin{tabular}{|c|c|c|c|c|}
\hline \multirow{2}{*}{ Variable } & \multicolumn{2}{|l|}{ Univariate } & \multicolumn{2}{|c|}{ Multivariate } \\
\hline & $\mathrm{HR}(95 \% \mathrm{Cl})$ & p-value & $\mathrm{HR}(95 \% \mathrm{Cl})$ & $\mathrm{p}$-value \\
\hline Age & $1.04(0.99-1.09)$ & 0.093 & & 0.083 \\
\hline Male sex & $22.40(0.06-8,171.43)$ & 0.302 & & \\
\hline Smoking & $3.35(0.8-13.98)$ & 0.098 & $3.31(0.78-14.08)$ & 0.105 \\
\hline Alcohol consumption & $2.54(0.61-10.6)$ & 0.201 & & \\
\hline Charlson comorbidity index & 1.58 (1.29-1.93) & $<0.001$ & $1.61(1.30-2.01)$ & $<0.001$ \\
\hline Tumor size & $1.06(0.84-1.34)$ & 0.624 & & \\
\hline \multicolumn{5}{|l|}{ Location } \\
\hline Upper, mid third & 1 & & & \\
\hline Lower third & $1.1(0.57-2.18)$ & 0.762 & & \\
\hline \multicolumn{5}{|l|}{ Depth of invasion } \\
\hline $\mathrm{m} 1, \mathrm{~m} 2$ & 1 & & & \\
\hline m3 & $0.98(0.38-2.54)$ & 0.965 & & \\
\hline \multicolumn{5}{|l|}{ Tumor shape } \\
\hline Flat & 1 & & & \\
\hline Non-flat & $1.76(0.87-3.56)$ & 0.115 & & \\
\hline \multicolumn{5}{|l|}{ Differentiation } \\
\hline Well, moderately- & 1 & & 1 & \\
\hline Poorly- & $3.68(0.85-15.83)$ & 0.085 & $2.28(0.47-11.16)$ & 0.307 \\
\hline \multicolumn{5}{|l|}{ Multiplicity of lesion } \\
\hline Solitary & 1 & & & \\
\hline Multiple & $1.61(0.49-5.28)$ & 0.429 & & \\
\hline \multicolumn{5}{|l|}{ Lymphovascular invasion } \\
\hline Absent & 1 & & & \\
\hline Present & NA & 0.67 & & \\
\hline \multicolumn{5}{|l|}{ Resection methods } \\
\hline Endoscopic & 1 & & 1 & \\
\hline Surgical & $1.19(0.57-2.52)$ & 0.636 & $1.68(0.71-3.98)$ & 0.238 \\
\hline
\end{tabular}

$\mathrm{HR}$, hazard ratio; $\mathrm{Cl}$, confidence interval; m1, intraepithelial; m2, lamina propria; m3, muscularis mucosae; NA, not applicable.

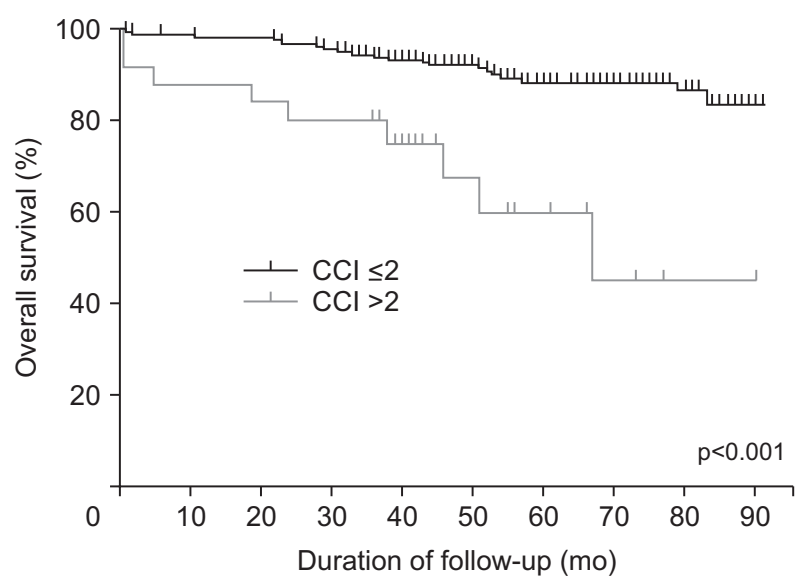

Fig. 3. Kaplan-Meier curves comparing overall survival according to the Charlson comorbidity index (CCI) score $(\leq 2$ and $>2$ ).

ing the submucosa (up to $200 \mu \mathrm{m}$ ) are also responsive to mucosal resection. ${ }^{22}$

The ER group was comparable to the SR group in terms of 5-year OS rate; however, the 5-year recurrence-free survival rate was lower in the ER group than in the SR group, especially, in cases with a higher occurrence of metachronous esophageal cancer. In this study, the 5-year cumu- lative incidence of locoregional recurrence of primary esophageal cancer was $1.5 \%$ and metachronous esophageal cancer recurrence was $9.0 \%$ in the ER group. Conversely, in the SR group, locoregional and metachronous recurrence were not reported. Metachronous esophageal cancer is a major concern following ER for T1aESCC. In a previous study, the incidence of metachronous esophageal cancer after endoscopic treatment was reported to be up to $14 \%{ }^{23}$ Tiny synchronous tumors might be missed at the initial endoscopic examination and might develop into visible recurrence during the 3.4-year surveillance period. ${ }^{23}$ Therefore, attention should be given to locoregional and metachronous recurrence after ER.

In previous studies, a 5 -year survival rate of $90 \%$ to $94 \%$ was reported in patients with T1aESCC who underwent esophagectomy. ${ }^{24,25}$ In cases of T1 ESCC with ER, the 5-year OS rates were reported to be $81.6 \%-99.0 \%$, and in subgroup analysis, 5 -year survival rates of patients with m1-2 and $\mathrm{m} 3$-sm 1 were reported to be $100 \%$ and $85 \%-$ $89.0 \%$, respectively. ${ }^{26,27}$ In our study, there were no esophageal cancer-related deaths in either group during follow-up.

Data were limited regarding long-term prognostic factors for patients with T1aESCC. The CCI is used for nu- 
merical conversion of comorbidities; as such, the CCI is widely established as a predictor for prognosis after multiple surgical procedures. ${ }^{28}$ Similar to the results of previous studies, we also found the CCI was the strongest prognostic factor (hazard ratio, 1.61; 95\% confidence interval, 1.3 to $2.01 ; \mathrm{p}<0.001) .{ }^{29,30}$ Our findings corroborate the study results that showed the influence of CCI on treatment outcomes in patients with esophageal cancer who underwent esophagectomy, ${ }^{29}$ in this study, the authors reported that the prognosis of patients with esophageal cancer who after curative esophagectomy was significantly correlated with the CCI.

Alcohol consumption and smoking are major risk factors for squamous cancers, ${ }^{31}$ and around $4.3 \%$ to $10.4 \%$ of patients with squamous esophageal cancer develop synchronous SPC. ${ }^{32}$ SPC associated with esophageal cancer commonly develop in the aerodigestive tract organs, such as the oral cavity, pharynx, larynx, and lung. ${ }^{32,33}$ In our study, 14 patients (9.1\%) were identified with subsequent SPC in both groups. The 5-year survival rates were significantly lower in patients with SPC compared with those without ( $46.4 \%$ and $90.5 \%$, respectively, $p=0.003$ ). Furthermore, SPC was the most important cause of death in the ER group.

This study has the following limitations. First, this study has a retrospective design based on consecutive observational data from a single tertiary referral center, which entails possible selection bias. Second, we did not analyze cost-effectiveness and the quality of life. Third, this study included a relatively small number of patients in the SR group and a small number of events, which hindered a detailed subgroup analysis and the detection of small differences with sufficient statistical power.

In conclusion, the long-term prognosis of patients with T1aESCC was significantly affected by underlying comorbidity. Although SR is a gold standard, ER is an excellent alternative therapy when strict endoscopic treatment of early esophageal cancer is indicated. Physicians should be aware of the possibility of metachronous esophageal cancer recurrence in patients undergoing ER and operationrelated adverse events in those undergoing SR.

\section{CONFLICTS OF INTEREST}

No potential conflict of interest relevant to this article was reported.

\section{AUTHOR CONTRIBUTIONS}

Study concept and design: H.J.S., Y.H.K., G.H.K. Data acquisition: H.K.N., J.Y.A., J.H.L., K.W.J., D.H.K., H.R.K., K.D.C., G.H.L., H.Y.J., S.I.P. Data analysis and interpretation: H.J.S., Y.H.K., G.H.K. Drafting of the manuscript: H.J.S., Y.H.K., G.H.K. Critical revision of the manuscript for important intellectual content: H.J.S., Y.H.K., G.H.K. Statistical analysis: G.H.K. Approval of final manuscript: all authors.

\section{ORICD}

Ga Hee Kim Hee Kyong $\mathrm{Na}$ https://orcid.org/0000-0002-7652-2580

Ji Yong Ahn https://orcid.org/0000-0001-6764-9099 Jeong Hoon Lee Kee Wook Jung https://orcid.org/0000-0002-0030-3744 https://orcid.org/0000-0002-0778-7585 https://orcid.org/0000-0002-3771-3691 Do Hoon Kim https://orcid.org/0000-0002-4250-4683 Hyeong Ryul Kim https://orcid.org/0000-0002-6691-7693 Kee Don Choi https://orcid.org/0000-0002-2517-4109 Ho June Song https://orcid.org/0000-0002-3195-8794 Yong-Hee Kim https://orcid.org/0000-0003-2177-4876 Gin Hyug Lee https://orcid.org/0000-0003-3776-3928 Hwoon-Yong Jung https://orcid.org/0000-0003-1281-5859 Seung-Il Park https://orcid.org/0000-0002-8729-0498

\section{REFERENCES}

1. Takubo K, Aida J, Sawabe M, et al. Early squamous cell carcinoma of the oesophagus: the Japanese viewpoint. Histopathology 2007;51:733-742.

2. Kim DU, Lee JH, Min BH, et al. Risk factors of lymph node metastasis in T1 esophageal squamous cell carcinoma. J Gastroenterol Hepatol 2008;23:619-625.

3. Fujiyoshi T, Tajika M, Tanaka T, et al. Comparative evaluation of new and conventional classifications of magnifying endoscopy with narrow band imaging for invasion depth of superficial esophageal squamous cell carcinoma. Dis Esophagus 2017;30:1-8.

4. Kitagawa Y, Uno T, Oyama T, et al. Esophageal cancer practice guidelines 2017 edited by the Japan esophageal society: part 2. Esophagus 2019;16:25-43.

5. Kitagawa Y, Uno T, Oyama T, et al. Esophageal cancer practice guidelines 2017 edited by the Japan Esophageal Society: part 1. Esophagus 2019;16:1-24.

6. Ishihara R, Arima M, Iizuka T, et al. Endoscopic submucosal dissection/endoscopic mucosal resection guidelines for esophageal cancer. Dig Endosc 2020;32:452-493.

7. Plum PS, Hölscher AH, Pacheco Godoy K, et al. Prognosis of patients with superficial T1 esophageal cancer who under- 
went endoscopic resection before esophagectomy: a propensity score-matched comparison. Surg Endosc 2018;32:39723980.

8. Wang S, Huang Y, Xie J, et al. Does delayed esophagectomy after endoscopic resection affect outcomes in patients with stage T1 esophageal cancer? A propensity score-based analysis. Surg Endosc 2018;32:1441-1448.

9. Draganov PV, Wang AY, Othman MO, Fukami N. AGA institute clinical practice update: endoscopic submucosal dissection in the United States. Clin Gastroenterol Hepatol 2019;17:16-25.

10. Zhang Y, Ding H, Chen T, et al. Outcomes of endoscopic submucosal dissection vs esophagectomy for T1 esophageal squamous cell carcinoma in a real-world cohort. Clin Gastroenterol Hepatol 2019;17:73-81.

11. Min YW, Lee H, Song BG, et al. Comparison of endoscopic submucosal dissection and surgery for superficial esophageal squamous cell carcinoma: a propensity score-matched analysis. Gastrointest Endosc 2018;88:624-633.

12. Travis WD, Brambilla E, Nicholson AG, et al. The 2015 World Health Organization classification of lung tumors: impact of genetic, clinical and radiologic advances since the 2004 classification. J Thorac Oncol 2015;10:1243-1260.

13. Pennathur A, Farkas A, Krasinskas AM, et al. Esophagectomy for T1 esophageal cancer: outcomes in 100 patients and implications for endoscopic therapy. Ann Thorac Surg 2009;87:1048-1054.

14. Chang AC, Ji H, Birkmeyer NJ, Orringer MB, Birkmeyer JD. Outcomes after transhiatal and transthoracic esophagectomy for cancer. Ann Thorac Surg 2008;85:424-429.

15. Connors RC, Reuben BC, Neumayer LA, Bull DA. Comparing outcomes after transthoracic and transhiatal esophagectomy: a 5-year prospective cohort of 17,395 patients. J Am Coll Surg 2007;205:735-740.

16. Das A, Singh V, Fleischer DE, Sharma VK. A comparison of endoscopic treatment and surgery in early esophageal cancer: an analysis of surveillance epidemiology and end results data. Am J Gastroenterol 2008;103:1340-1345.

17. Choi JY, Park YS, Jung HY, et al. Feasibility of endoscopic resection in superficial esophageal squamous carcinoma. Gastrointest Endosc 2011;73:881-889.

18. Stein HJ, Feith M, Bruecher BL, Naehrig J, Sarbia M, Siewert JR. Early esophageal cancer: pattern of lymphatic spread and prognostic factors for long-term survival after surgical resection. Ann Surg 2005;242:566-573.

19. Kodama M, Kakegawa T. Treatment of superficial cancer of the esophagus: a summary of responses to a questionnaire on superficial cancer of the esophagus in Japan. Surgery 1998;123:432-439.

20. Pimentel-Nunes P, Dinis-Ribeiro M, Ponchon T, et al. Endoscopic submucosal dissection: European Society of
Gastrointestinal Endoscopy (ESGE) Guideline. Endoscopy 2015;47:829-854.

21. Ajani JA, D'Amico TA, Bentrem DJ, et al. Esophageal and esophagogastric junction cancers, version 2.2019, NCCN clinical practice guidelines in oncology. J Natl Compr Canc Netw 2019;17:855-883.

22. Shimizu Y, Tsukagoshi H, Fujita M, Hosokawa M, Kato M, Asaka M. Long-term outcome after endoscopic mucosal resection in patients with esophageal squamous cell carcinoma invading the muscularis mucosae or deeper. Gastrointest Endosc 2002;56:387-390.

23. Sgourakis G, Gockel I, Lang H. Endoscopic and surgical resection of $\mathrm{T} 1 \mathrm{a} / \mathrm{T} 1 \mathrm{~b}$ esophageal neoplasms: a systematic review. World J Gastroenterol 2013;19:1424-1437.

24. Wijnhoven BP, Tran KT, Esterman A, Watson DI, Tilanus HW. An evaluation of prognostic factors and tumor staging of resected carcinoma of the esophagus. Ann Surg 2007;245:717-725.

25. Hölscher AH, Bollschweiler E, Schröder W, Metzger R, Gutschow C, Drebber U. Prognostic impact of upper, middle, and lower third mucosal or submucosal infiltration in early esophageal cancer. Ann Surg 2011;254:802-807.

26. Nagami Y, Ominami M, Shiba M, et al. The five-year survival rate after endoscopic submucosal dissection for superficial esophageal squamous cell neoplasia. Dig Liver Dis 2017;49:427-433.

27. Ono S, Fujishiro M, Niimi K, et al. Long-term outcomes of endoscopic submucosal dissection for superficial esophageal squamous cell neoplasms. Gastrointest Endosc 2009;70:860866.

28. Charlson ME, Pompei P, Ales KL, MacKenzie CR. A new method of classifying prognostic comorbidity in longitudinal studies: development and validation. J Chronic Dis 1987;40:373-383.

29. Yamashita K, Watanabe M, Mine S, et al. The impact of the Charlson comorbidity index on the prognosis of esophageal cancer patients who underwent esophagectomy with curative intent. Surg Today 2018;48:632-639.

30. Bernardi D, Asti E, Aiolfi A, Bonitta G, Luporini A, Bonavina L. Outcome of trimodal therapy in elderly patients with esophageal cancer: prognostic value of the Charlson comorbidity index. Anticancer Res 2018;38:1815-1820.

31. Layke JC, Lopez PP. Esophageal cancer: a review and update. Am Fam Physician 2006;73:2187-2194.

32. Nagasawa S, Onda M, Sasajima K, Takubo K, Miyashita M. Multiple primary malignant neoplasms in patients with esophageal cancer. Dis Esophagus 2000;13:226-230.

33. Matsubara T, Yamada K, Nakagawa A. Risk of second primary malignancy after esophagectomy for squamous cell carcinoma of the thoracic esophagus. J Clin Oncol 2003;21:43364341. 